RESUMEN DE TESIS

\title{
FISIOLOGÍA DE HONGOS FILAMENTOSOS: EFECTO DEL ZN Y MN*
}

\author{
Claudia M. Ibáñez ${ }^{1}$
}

\begin{abstract}
RESUMEN
Se estudió el uso de las sales de $\mathrm{Zn}$ y Mn como preservantes para maderas. Su eficacia se evaluó empleando sales puras como aquellas provenientes de un proceso de reciclado. Este proceso hidrometalúrgico de reciclado de pilas comunes y alcalinas fue desarrollado en laboratorios propios de la Universidad de la República; fue de bajo costo y permitió el aprovechamiento de los materiales que contienen. El producto principal fue una solución de $\mathrm{Zn}$ y Mn.

Los hongos causantes de pudrición blanca en la madera empleados fueron Phanerochaete chrysosporium y Punctularia atropurpurascens, que poseen diferente sistema ligninolítico. El efecto de los metales se estudió analizando el crecimiento (desarrollo micelial y germinación de conidios) y la función ligninolítica (actividad enzimática de las peroxidasas y expresión de los genes que codifican manganeso peroxidasas).

Se constató actividad antifúngica en la solución proveniente del reciclado y en la mezcla de sales puras de $\mathrm{Zn}-\mathrm{Mn}$, con crecimiento sobre madera o medio nutriente. La solución se lixivia de la madera, por eso para el ensayo de campo, se aplicó borax a las probetas ya tratadas con la solución; a 24 meses su efectividad fue comparable con la del CCA. La solución y la mezcla de sales puras fueron inhibidoras de la función ligninolítica a todo nivel. En términos generales el Mn tendió a inducir los parámetros del metabolismo estudiados, con la excepción de la germinación de conidios y la expresión de los genes MnP de P. chrysosporium. Se identificaron al menos $7 \mathrm{MnP}$ de P.atropurpurascens con alta similaridad con $\mathrm{MnP}$ de otros basidiomycetes.
\end{abstract}

\footnotetext{
${ }^{1}$ Doctora en Química, Unidad Académica de Gestión Tecnológica, Facultad de Química. Universidad de la República, Avda. Gral. Flores 2124, Montevideo, Uruguay.

Autor para correspondencia: cmibanes@gmail.com

Recibido: 10.05.2011

Aceptado: 06.09.2011

* Tesis presentada en conformidad a los requisitos para obtener el título de Doctor en Química, Departamento Tecnológico, Facultad de Química, Universidad de la República, Montevideo, Uruguay, diciembre 2010.
} 
